\title{
Autoecologia de Guadua aff. paraguayana (Poaceae)
}

\author{
Franklin Galvão(1), Cátia Regina Augustin(1), Gustavo Ribas Curcio(2), Bruno Polli Domanowski(1), Carina Kozera(1), \\ Alison Tadeu Sawczuk ${ }^{(1)}$, Annete Bonnet(1)
}

\begin{abstract}
(1) Universidade Federal do Paraná - UFPR, Avenida Prefeito Lothário Meissner, 632, CEP 80210-170, Jardim Botânico, Curitiba-PR. E-mail: fgalvao@ufpr.br, catiaraugustin@gmail.com, brunopolli@hotmail.com, carinakozera@yahoo.com.br, alison.tadeu@gmail.com, a_bonnet@hotmail.com; (2) Embrapa Florestas, Estrada da Ribeira, Km 111, CP 319, CEP 83411-000, Colombo-PR. E-mail: curcio@cnpf.embrapa.br
\end{abstract}

\begin{abstract}
Resumo - Bambus são agentes de remediação natural, mas sua irrupção numa paisagem já estabelecida pode ter repercussão intensa, alterando completamente a florística da área. Para estabelecer os efeitos da presença de Guadua aff. paraguayana Döll (Poaceae) - um dos pouco conhecidos bambus maciços do planeta - sobre os últimos remanescentes da Floresta Ombrófila Mista Aluvial, nas áreas de preservação permanente do Refúgio de Vida Silvestre do Rio Tibagi, unidade de conservação em processo de criação no Segundo Planalto Paranaense, está-se desenvolvendo o estudo de sua autoecologia. Esta espécie lenhosa, agressiva e oportunista, forma touceiras vigorosas devido ao desenvolvimento de rizomas do tipo paquimorfo de pescoço curto e se estabelece apenas nas feições mais projetadas da planície aluvial degradada. As touceiras têm área média de $2,79 \mathrm{~m}^{2}$, com $11 \mathrm{colmos} / \mathrm{m}^{2}$. A fase de brotação dura, em média, quatro meses e ocorre entre a primavera e o verão. Os colmos têm comprimento médio de $13 \mathrm{~m}$, com incremento de $18 \mathrm{~cm} /$ dia no período de estiramento. O diâmetro médio a 1,30 m é de 4,25 cm. As touceiras são formadas por apenas um indivíduo que se expande a partir de brotações extremamente robustas. Quando superam o dossel e recebem radiação direta, formam uma espécie de trançado de ramos e folhas capaz de aumentar fortemente o sombreamento e suprimir a vegetação instalada, modificando os padrões de sucessão local.
\end{abstract}

Termos para indexação: Floresta Ombrófila Mista, planície aluvial degradada, bambu.

\section{Auto-ecology of Guadua aff. paraguayana (Poaceae)}

\begin{abstract}
Bamboos are agents of natural remediation, but its outbreak in an already established landscape may have an intense repercussion, completely changing the flora of the area. A study to determine the effects of the presence of Guadua aff. paraguayana Döll (Poaceae) found in the last remnants of the riparian forest in the areas of permanent preservation of the Wildlife Refuge of Rio Tibagi - a conservation unit in process of stablishment on the Parana's second plateau, has been developed. This aggressive and opportunistic woody species develops vigorous tussocks in consequence of its pachymorph rhizome system a form of "short neck"; and gets established only on the higher portions of the degraded flood plain. The tussocks have an average size of 2.79 meters, with $11 \mathrm{stems} / \mathrm{m}^{2}$. The shooting season lasts, on average, four months and occurs between spring and summer. The culms have an average length of $13 \mathrm{~m}$, with an increment of $18 \mathrm{~cm} /$ day during the stretch period. The average diameter at breast height is $4.25 \mathrm{~cm}$. The tussocks are formed from only one stem that expands from extremely robust sprouts. When it shoots up over the canopy and receives direct sunlight, it forms a kind of braided branches and leaves capable of hardly increase the shade levels and suppress the established vegetation, changing the local succession patterns.
\end{abstract}

Index terms: Riparian forest, degraded flood plain, bamboo, Poaceae

\section{Introdução}

A ocupação de áreas cada vez mais extensas nas planícies fluviais do Refúgio de Vida Silvestre do Rio Tibagi, unidade de conservação federal em processo de criação, destinada a preservar os últimos remanescentes de Floresta Ombrófila Mista Aluvial (FOMA) em bom estado no Segundo Planalto Paranaense, por uma espécie, segundo Ohrnberger (1999) e Filgueiras e Gonçalves
(2004), nativa de bambu - Guadua aff. ${ }^{1}$ paraguayana Döll (Poaceae, Bambusoideae) - pode estar pondo em risco a biodiversidade local, ao uniformizar a ${ }^{1}$ Aff.: do latim affinis, morfologicamente semelhante, parecido ou considerado filogeneticamente parente próximo (FONT QUER, 1979). Apesar de a floração gregária e monocárpica dos bambus ser uma regra que admite, principalmente no gênero Guadua, muitas exceções, nenhuma parte fértil foi observada durante o período de estudo. A identificação foi feita a partir de características vegetativas, o que não permitiu uma avaliação conclusiva. 
paisagem.

O Refúgio de Vida Silvestre do Rio Tibagi, além de proteger uma área prevista em 31.698 ha, deve funcionar como corredor de biodiversidade, fazendo a conexão entre o Parque Nacional dos Campos Gerais, a Reserva Biológica de Imbituva, a Área de Proteção Ambiental (APA) da Escarpa Devoniana e o Parque Estadual de Vila Velha (BRASIL, 2005).

A presença maciça deste bambu nas áreas de preservação permanente do Alto Tibagi revela o elevado grau de degradação destes espaços submetidos a intensa pressão de uso. O Tibagi forma a terceira maior bacia hidrográfica do estado do Paraná. Com 616 km de extensão, nasce no Município de Ponta Grossa e deságua ao norte, no Rio Paranapanema (IPARDES, 2008). Suas cabeceiras estão sobre o arenito Furnas, a 1.080 m s.n.m.

Tradicional rota de tropeiros no século 18, o segundo planalto paranaense abrigou, até a primeira metade do século 20 , a criação extensiva de gado para produção de carne e leite. Há 60 anos, os campos naturais deram lugar a pastagens de melhor qualidade e a culturas anuais como milho, soja e trigo. O desaparecimento da cobertura vegetal nativa trouxe graves problemas de erosão hídrica. Com os altos índices de precipitação da região, os solos que já eram, em sua maioria, rasos, com baixa saturação de bases, de textura média a arenosa e estrutura fraca - condições agravadas pelo elevado comprimento e declividade das vertentes -, não suportaram o sistema convencional de cultivo (SÁ, 2007). Duas décadas depois, o plantio direto e a rotação de culturas minimizaram a erosão, mas não asseguraram a preservação do ambiente.

Os equívocos no uso agrícola do solo, o desmatamento, a urbanização crescente e mais de 50 anos de mineração de areia repercutiram intensamente na modelagem da planície aluvial, edificando áreas com solos alterados e possibilitando a propagação de espécies agressivas e oportunistas, como os bambus.

\section{Bambus}

Por sua habilidade em tirar rápida vantagem de pequenas ou grandes perturbações ambientais, bambus podem ter um efeito profundo na dinâmica da vegetação de uma área. Invasoras especializadas, a reprodução vegetativa, associada às formas dos rizomas, confere aos bambus grande capacidade de ocupação de novos ambientes, como, por exemplo, clareiras abertas na floresta (JUDZIEWICZ et al., 1999).

Os bambus apresentam folhas pseudopecioladas, ramificação complexa e florescimento geralmente monocárpico e gregário, características que podem ser eficientes adaptações à intensa competição por luz. O hábito também está diretamente relacionado à estratégia da espécie para obtenção de energia. Os bambus de grande estatura, como muitas das espécies de Guadua, têm colmos essencialmente eretos e autossustentados, às vezes, arqueados nas pontas, onde predominam as folhas fotossintetizantes. Os colmos nem sempre são ocos. Entrenós completamente sólidos são característicos de Chusquea e estão presentes em certas espécies de gêneros como Merostachys, Guadua e Neurolepis (JUDZIEWICZ et al., 1999)

Mudanças nos colmos distinguem o desenvolvimento vegetativo dos bambus. São convencionalmente quatro fases: brotação, juvenil, adulta e senil ou seca. Internamente, o amadurecimento do colmo é marcado pela lignificação dos tecidos, espessamento das paredes das fibras e perda de umidade. Externamente, a brotação começa com a emissão de um novo colmo e termina em seu estiramento máximo. A fase juvenil inicia com a queda das folhas caulinares e com o desenvolvimento dos galhos e folhas da ramagem. Mas nem sempre a passagem de fase é bem marcada. A fase adulta é caracterizada pela mudança da cor verde brilhante para um verde mais opaco. Na fase seca ou senil, uma indicação de que o colmo começou a envelhecer, os entrenós ficam amarelados e os galhos da porção média secam (LONDOÑO, 1993). Em Guadua, a defesa contra herbivoria pode incluir a modificação de ramos em espinhos. Este é o único gênero de bambu americano a apresentar esta alteração (JUDZIEWICZ et al., 1999).

O Brasil é o país com maior diversidade em espécies de bambu nas Américas, com 34 gêneros e 232 espécies, das quais $75 \%$ (174 espécies) são consideradas endêmicas. Estão presentes aqui $89 \%$ dos gêneros conhecidos e cerca de $65 \%$ das espécies de bambus do Novo Mundo (FILGUEIRAS; GONÇALVES, 2004).

\section{O gênero Guadua}

Guadua Kunth (Sinonímia: Bambusa Schreber subgênero Guadua (Kunth) Hack. (MISSOURI BOTANICAL GARDEN, 2008) é um gênero de bambus lenhosos, com colmos desde eretos e arqueados no ápice a escandentes, de porte médio a grande, com 5-20 (-30) m de comprimento e 2-15 (-22) cm de diâmetro 
(LONDOÑO, 2001). Podem apresentar rizomas de pescoços curtos a longos. Colmos ocos são encontrados na maioria das espécies, mas em $G$. paraguayana podem ser maciços. Frequentemente exibem uma característica faixa de tricomas brancos curtos na linha do nó. Os entrenós costumam ser sulcados acima da inserção da gema do ramo (JUDZIEWICZ et al., 1999). Os ramos são espinescentes na maioria das espécies e as folhas caulinares são decíduas. As folhas dos ramos têm lâminas maiores nas plantas jovens e menores nas adultas (LONDOÑO, 2001), são pseudopecioladas, com limbos lineares a lanceolados-ovados (JUDZIEWICZ et al., 1999).

As 24 espécies de Guadua atualmente descritas crescem do México ( $23^{\circ} \mathrm{N}$, G. velutina) ao Uruguai e Argentina ( $35^{\circ} \mathrm{S}, G$. trinii), de 0 a $2.200 \mathrm{~m}$ s.n.m., sendo mais abundantes e diversas abaixo de $1.500 \mathrm{~m}$ s.n.m. Guaduas ocorrem em vários hábitats, da planície tropical e cerrados a florestas de encosta e fluviais (JUDZIEWICZ et al., 1999).

Devido à sua reprodução vegetativa, em campo, é quase impossível dizer onde termina um indivíduo e onde começa outro. Um indivíduo de Guadua é capaz de cobrir hectares e pode ser, com seus altos colmos lenhosos e sua enorme biomassa de rizomas no subsolo, o maior organismo do mundo (JUDZIEWICZ et al., 1999).

\section{Floresta Ombrófila Mista Aluvial}

As margens do Tibagi, hoje em parte ocupadas por $G$. aff. paraguayana, são território da Floresta Ombrófila Mista Aluvial (FOMA). Esta formação ocorre em relevos planos e suave-ondulados, constituídos por solos de elevado grau de hidromorfia, como Neossolos Flúvicos e Gleissolos Háplicos. Nestes locais, a espécie arbórea por excelência é Sebastiania commersoniana (Baill) L. B. Sm. \& Downs (branquilho) (PASDIORA, 2003, BARDDAL et al., 2004, CURCIO et al., 2007). Nas áreas com menor saturação hídrica, está Araucaria angustifolia (Bertol.) Kuntze (Araucariaceae), o pinheiro-do-paraná. Também no dossel desta formação, destacam-se Schinus terebinthifolius Raddi (Anacardiaceae), Blepharocalyx salicifolius (Kunth) O. Berg (Myrtaceae), Matayba elaeagnoides Radlk. (Sapindaceae) e Vitex megapotamica (Spreng.) Moldenke (Lamiaceae). São menos frequentes Luehea divaricata Mart. (Tiliaceae), Syagrus romanzoffiana (Cham.) Glassman (Arecaceae), Erythrina crista-galli L. (Fabaceae) e Salix humboldtiana Willd. (Salicaceae). Nos estratos inferiores são comuns Myrciaria tenella O. Berg, Myrceugenia euosma (O. Berg) D. Legrand, Calyptranthes concinna DC. (Myrtaceae), Allophylus edulis Radlk. ex Warm. (Sapindaceae), Daphnopsis racemosa Griseb. (Thymelaeaceae) e Psychotria carthagenensis Jacq. (Rubiaceae) (DIAS, 1998; RODERJAN et al., 2002, CARMO et al., 2007).

Em estudo recente, a influência de $G$. aff. paraguayana sobre as espécies arbóreas desta floresta aluvial foi evidenciada pelas reduzidas densidade e vitalidade dos indivíduos remanescentes. Nesta área, há diminuição ou quase ausência de sub-bosque, de epifitismo vascular e de espécies em regeneração. Chama particularmente a atenção o percentual de árvores agonizantes (classe de vitalidade 3): cerca de $68 \%$ em presença de $G$. aff. paraguayana contra $11 \%$ nas áreas onde a espécie está ausente (POZZOBON et al., 2009).

Para entender a relação de causa e efeito entre a degradação da área e a predominância de $G$. aff. paraguayana, buscou-se estabelecer aspectos relacionados à autoecologia da espécie.

\section{Material e Métodos}

\section{Localização e caracterização da área em estudo}

A área em estudo está situada no Município de Ponta Grossa, PR, nas coordenadas $25^{\circ} 13^{\prime} 20,8^{\prime}$ ' S e $50^{\circ} 04^{\prime}$ 26,8' W, em zona de amortecimento de quatro unidades de conservação: APA da Escarpa Devoniana, Parque Estadual Vila Velha, Parque Nacional dos Campos Gerais e Refúgio de Vida Silvestre do Rio Tibagi (Figura 1). 


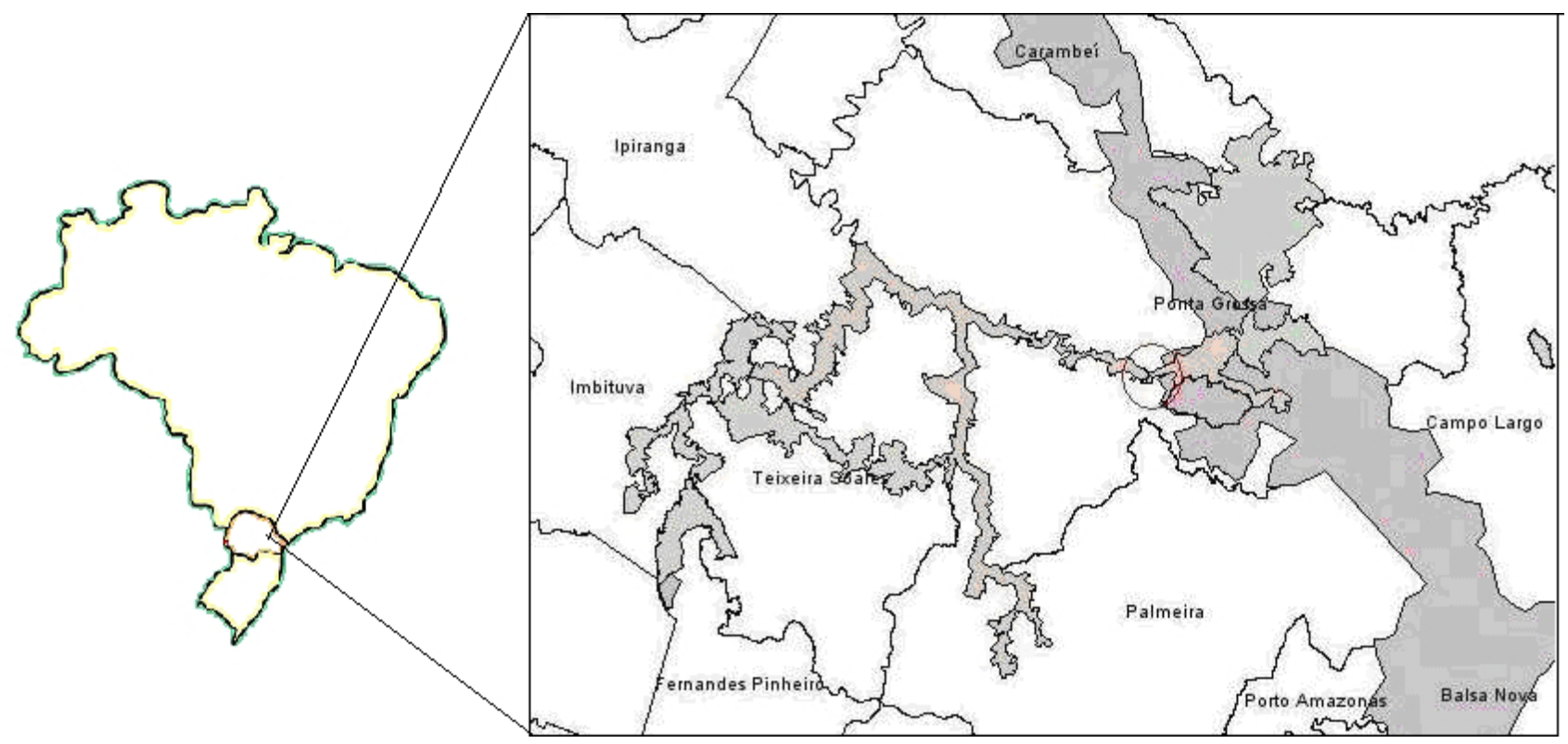

Figura 1. Localização da área de estudo, com destaque para as unidades de conservação existentes na região (BRASIL, 2005).

A litologia da região é formada pelo arenito Furnas (MINEROPAR, 1989), onde originalmente predominava Estepe com ocorrências esparsas de Floresta Ombrófila Mista. A planície apresenta geomorfologia caracterizada por barras e interbarras, constituídas por Cambissolos Flúvicos e Gleissolos Háplicos, respectivamente. Nos diques marginais, destacam-se os Neossolos Flúvicos.

O clima, segundo Köppen, é dominantemente do tipo $\mathrm{C} f b$, subtropical úmido mesotérmico, com temperatura média anual de $18-19{ }^{\circ} \mathrm{C}$, com mínima de $13{ }^{\circ} \mathrm{C}$ e máxima de $24{ }^{\circ} \mathrm{C}$. Na maior parte da área, os índices pluviométricos situam-se entre $1.400 \mathrm{~mm}$ e $1.600 \mathrm{~mm}$ anuais (MAACK, 1981; IAPAR, 1994; CRUZ, 2007).
Para avaliar a profundidade e a variação de nível do lençol freático, foram instalados cinco poços hídricos (Figura 2), respeitando-se as características geomorfológicas da área. Dois deles foram posicionados em interbarras e três nas regiões alçadas (dique marginal e barras). Os dados foram coletados mensalmente durante o período de janeiro a dezembro de 2007. Para o estabelecimento do perfil do relevo, foram realizadas cotações altimétricas de metro em metro, com o auxílio de uma trena e um nível, no sentido rio-planície de inundação. A caracterização pedológica foi feita conforme Santos et al. (2005).

\section{$110 \mathrm{~cm}$}

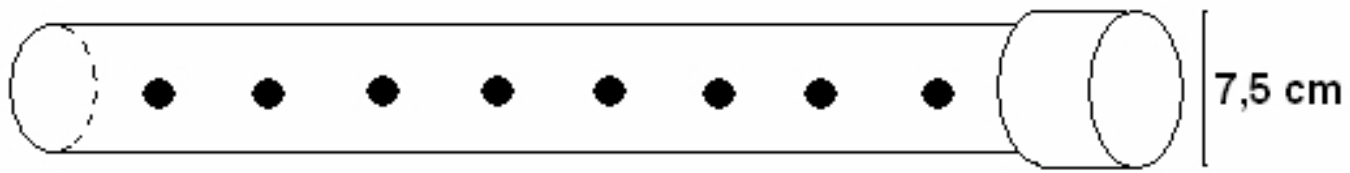

Figura 2. Desenho esquemático dos poços hídricos. 
No estudo da autoecologia de $G$. aff. paraguayana, foram alocadas, sistematicamente, parcelas quadradas (oito, com $100 \mathrm{~m}^{2}$ de área cada uma), em condição de barra. Nelas, foram coletados dados sobre o número de touceiras, quantidade e distribuição de colmos por touceira e DAP (diâmetro à altura do peito - 1,30 m) dos colmos. Foram identificados, contados e medidos os indivíduos arbóreos com DAP igual ou maior do que $5 \mathrm{~cm}$, e os descritores fitossociológicos e a diversidade calculados, respectivamente, conforme MuellerDombois e Ellenberg (1974) e Magurran (1989).

A biomassa foi determinada a partir de seis colmos adultos de touceiras diversas. Foram separados, medidos e pesados folhas caulinares e fotossintetizantes, galhos, colmos e rizomas. A umidade foi determinada com secagem em estufa de ventilação forçada a $60 \pm 2{ }^{\circ} \mathrm{C}$ do material coletado.

Para acompanhar o volume, a regularidade da deposição e a composição da serapilheira, 36 coletores cônicos, com $50 \mathrm{~cm}$ de diâmetro de abertura, foram dispostos a $50 \mathrm{~cm}$ do solo, ao longo de barras e interbarras, ou seja, em áreas com presença e ausência de $G$. aff. paraguayana. Para o estudo, em andamento, da velocidade de decomposição da serapilheira, foram coletadas folhas da ramagem (lâminas e bainhas) com até um mês de deposição. Foram utilizados 84 sacos de decomposição medindo $15 \mathrm{~cm}$ x $20 \mathrm{~cm}$, confeccionados em nylon, com malha de $2 \mathrm{~mm}$ de diâmetro, dispostos em quatro parcelas, duas em barra (lâminas e bainhas foliares) e duas em interbarras (apenas lâminas). A cada dois meses, 12 sacos (oito de lâminas e quatro de bainhas) são coletados para análise.

\section{Resultados e Discussão}

Nas barras e diques marginais, é expressiva a presença de Guadua aff. paraguayana, que se impõe sobre a floresta formada principalmente por Sebastiania commersoniana. Nas interbarras, a saturação hídrica do solo dificulta o estabelecimento da vegetação, sobretudo do componente arbóreo.

A análise morfológica do solo revelou serem as barras constituídas por Depósito Psamítico Distrófico gleizado (classe não prevista em Santos et al., 2006) e Neossolo Flúvico Tb Distrófico gleizado, de textura média a arenosa. As interbarras são formadas por Gleissolo Melânico Distrófico típico (SANTOS, 2006), com textura argilosa e com predominância de microporos, que retêm a umidade por mais tempo, dificultando as trocas gasosas e o estabelecimento da vegetação.

Houve diminuição do nível de hidromorfia do solo. O aporte de sedimentos gerados pela erosão hídrica - herança de técnicas agrícolas inadequadas -, o desmatamento, o rebaixamento do lençol freático causado pelos anos de intensa mineração de areia no leito do rio e o comportamento meandrante e divagante do Tibagi, neste trecho, contribuíram para o alçamento natural das barras.

Os dados coletados nos poços hídricos, nas datas de registro, demonstraram estar o lençol a uma profundidade média de $95 \mathrm{~cm}$ nas barras (Figura 3). As observações dos perfis de solo, no entanto, revelaram a ocorrência de gleização já a $10 \mathrm{~cm}$ abaixo da superfície. Esta diferença indica que a saturação existente hoje é apenas sazonal, provocada pela ascensão do lençol ou por cheias, quando há transbordamento. A coloração acinzentada e o mosqueamento observados revelam que a linha do talvegue do rio, num dado momento, esteve mais elevada, provocando saturação hídrica permanente próxima à superfície.

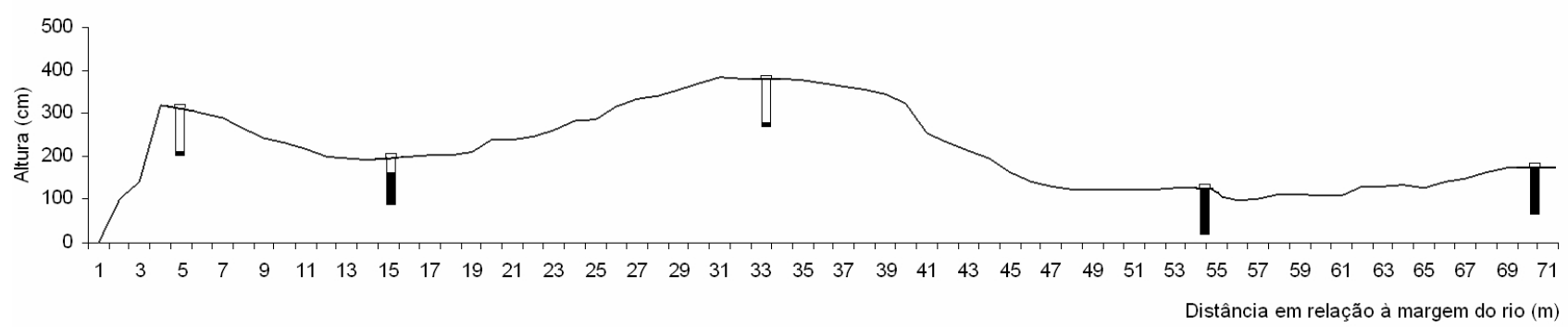

Figura 3. Perfil do terreno com indicação (dentro das representações esquemáticas dos poços hídricos) da profundidade do lençol freático. 
Os resultados obtidos sugerem ser provável a relação entre a saturação hídrica do terreno e a presença de $G$. aff. paraguayana. Nas barras, onde a espécie é predominante, a área que permanece livre de excesso de água, nas datas de registro, apresenta profundidade mínima de $1 \mathrm{~m}$. Nas interbarras, feições, em média, com cotas $2 \mathrm{~m}$ mais baixas, o lençol freático chegou à superfície recorrentemente. Nestes locais, G. aff. paraguayana não se estabelece.

O impacto de $G$. aff. paraguayana na estrutura da floresta pode ser quantificado por indicadores fitossociológicos. A espécie apresenta, em condição de barra, 250 touceiras/ha e dominância absoluta de $11,12 \mathrm{~m}^{2} /$ ha, o equivalente a $25 \%$ de uma área basal total de $44,42 \mathrm{~m}^{2} /$ ha. Quando a dominância absoluta é calculada a partir da projeção da porção apical dos colmos (que desempenha aqui a função de copa), $G$. aff. paraguayana soma $29.875 \mathrm{~m}^{2} /$ ha, numa cobertura total de $78.625 \mathrm{~m}^{2} / \mathrm{ha}$, ou $39 \%$. A espécie ocupa o segundo lugar no valor de importância (VI), resultado dos elevados valores de dominância e frequência relativas. Em terceira posição de VI, aparecem as árvores mortas. $\mathrm{O}$ índice de diversidade de Shannon (H') (MAGURRAN, 1989) foi de 1,39 nats/ind., o que revela uma comunidade com diversidade relativamente baixa. $\mathrm{O}$ valor de equabilidade (J) de 0,469 evidencia o predomínio de poucas espécies: o branquilho, presente em todas as parcelas, o guadua e a embira (Daphnopsis sp.). Das 15 espécies arbóreas presentes, as quatro principais em valor de importância, computando-se ainda Guadua e mortas, representam quase a totalidade dos índices fitossociológicos considerados (Tabela 1).

As características estruturais desta comunidade - predomínio de guadua, mortalidade de indivíduos adultos, baixo recrutamento - , mais do que o pequeno número de espécies - fato bastante comum nestes ambientes -, são indícios da degradação recorrente e de restrições à regeneração natural. Estudos realizados por Filgueiras (1988) e Oliveira Filho et al. (1994) destacam a influência que os bambus exercem sobre a regeneração natural.

G. aff. paraguayana possui colmos grandes (Tabela 2) e maciços (Figura 4F), em acordo com a descrição feita por Ohrnberger (1999) e Londoño (2008), para Guadua paraguayana, e apresenta, graças a rizomas paquimorfos de pescoço curto (Figura 5), um vigoroso crescimento em touceiras (Figura 4B). Na planta adulta, os rizomas têm, em média, $78,80 \%$ de umidade e $250,80 \mathrm{~g}$ de matéria seca. Neste tipo de touceira, a circunferência do rizoma, tomada na parte mais espessa, tem, em média, $33 \mathrm{~cm}$. Seu comprimento médio é de $33,5 \mathrm{~cm}$. As touceiras analisadas apresentam área média de $2,79 \mathrm{~m}^{2}$, com 11 colmos $/ \mathrm{m}^{2}$, distribuídos de maneira radial. Os colmos mais jovens estão posicionados perifericamente, e os mais velhos, no centro, exibindo características de senilidade. Este padrão pode, porém, ser alterado em touceiras longevas.

Tabela 1. Densidade relativa (DR), Dominância relativa (DoR), Frequência relativa (FR), Frequência absoluta (FA) e Valor de importância (VI) das espécies predominantes no dique marginal da planície fluvial do Rio Tibagi, Município de Ponta Grossa, PR.

\begin{tabular}{lrrrrr}
\hline Espécies & \multicolumn{1}{c}{ DR } & DoR & FR & FA & \multicolumn{1}{c}{ VI } \\
\hline Sebastiania commersoniana & 65,28 & 64,34 & 28,57 & 100,00 & 158,19 \\
Guadua aff. paraguayana & 9,26 & 25,04 & 12,50 & 43,75 & 46,80 \\
Daphnopsis cf. fasciculata & 3,24 & 2,28 & 8,93 & 31,25 & 14,45 \\
Vitex megapotamica & 2,31 & 0,93 & 3,57 & 12,50 & 6,82 \\
Guettarda uruguensis & 0,93 & 0,11 & 3,57 & 12,50 & 4,61 \\
Árvores mortas & 12,50 & 4,44 & 19,64 & 68,75 & 36,58 \\
Demais espécies & 6,48 & 2,86 & 23,22 & 81,26 & 32,55 \\
\hline
\end{tabular}




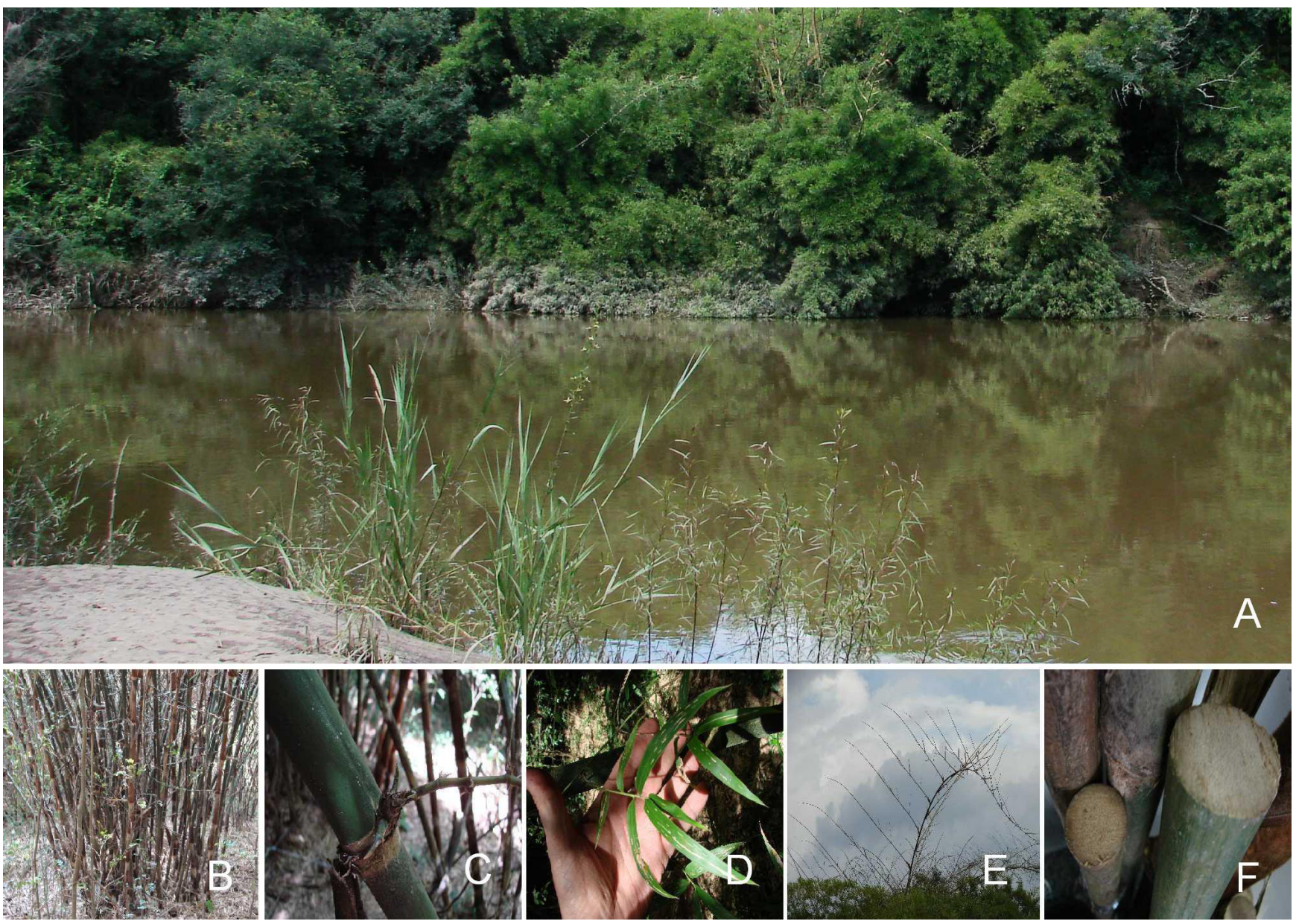

Figura 4. A: Paisagem alterada pela presença de Guadua aff. paraguayana, Rio Tibagi, Ponta Grossa, PR; B: Padrão de crescimento em touceiras; C: Espinhos tipo garra característicos do gênero Guadua; D: Folhas fotossintetizantes lanceoladas; E: Aspecto de "quilha de navio" dos galhos emergentes; F: Colmos maciços.

Embora na descrição de Londoño (2008) os colmos apresentem de $3 \mathrm{~m}$ a $10 \mathrm{~m}$ de altura e na de Ohrnberger (1999) de $8 \mathrm{~m}$ a $10 \mathrm{~m}$, o comprimento médio dos indivíduos observados em campo foi de $13 \mathrm{~m}$ (Tabela 2), podendo alcançar $18 \mathrm{~m}$, com projeção da porção apical num raio de $10 \mathrm{~m}$ a $12 \mathrm{~m}$. A produção de novos colmos se deu entre outubro e fevereiro, na temporada 2006/2007, e entre dezembro e abril, no verão 2007/2008. A brotação pode estar, conforme Judziewicz et al. (1999), atrelada ao regime de chuvas. Durante esta fase, o crescimento médio é de $18 \mathrm{~cm} /$ dia, podendo atingir picos de $75 \mathrm{~cm} / \mathrm{dia}$, no auge do período de estiramento. A circunferência média é de $9,18 \mathrm{~cm}$ (Tabela 2). Nas touceiras consolidadas, cada colmo adulto tem, em média, 44 entrenós, perímetro de $12,65 \mathrm{~cm}$ na base e de 2,38 cm no ápice. O DAP médio dos colmos obtido no levantamento fitossociológico foi de $4,25 \mathrm{~cm}$, maior que o encontrado para o diâmetro basal do estudo da biomassa, por ter sido este realizado com uma amostra bem menor de indivíduos.

Enquanto $S$. commersoniana leva, em média, 5,56 anos para atingir $1,30 \mathrm{~m}$ de altura (COSTENARO, et al., 2006), G. aff. paraguayana pode ultrapassar esta altura em menos de uma semana, com agravante de lançar-se em touceiras, com vários colmos crescendo simultaneamente. 
Tabela 2. Dados biométricos e coeficiente de variação (CV \%) de Guadua aff. Paraguayana.

\begin{tabular}{lrrrrr}
\hline Fração & Média & Máx. & Mín. & Desvio padrão & CV \% \\
\hline Perímetro basal (cm) & 12,65 & 15,00 & 11,60 & 1,61 & 12,74 \\
Perímetro médio (cm) & 9,18 & 10,30 & 7,80 & 1,27 & 13,80 \\
Perímetro apical (cm) & 2,38 & 3,30 & 1,40 & 0,79 & 33,40 \\
Comprimento colmo (m) & 13,01 & 15,45 & 11,28 & 1,84 & 14,13 \\
Número de entrenós & 44,25 & 52,00 & 39,00 & 6,02 & 13,61 \\
Número de galhos & 37,00 & 50,00 & 26,00 & 10,39 & 28,09 \\
Umidade do colmo (\%) & 56,19 & 63,10 & 51,04 & 5,34 & 9,50 \\
Umidade dos galhos (\%) & 44,54 & 53,80 & 39,43 & 6,47 & 14,53 \\
Umidade das folhas (\%) & 53,66 & 60,07 & 45,65 & 6,18 & 11,51 \\
Biomassa do colmo (kg) & 4,16 & 5,21 & 2,69 & 1,06 & 25,59 \\
Biomassa dos galhos (kg) & 1,50 & 1,90 & 1,17 & 0,30 & 20,22 \\
Biomassa das folhas (kg) & 1,63 & 2,38 & 0,60 & 0,82 & 50,53 \\
\hline
\end{tabular}

O teor de umidade dos colmos adultos é de $56,19 \%$ e o peso médio da matéria seca é de 7,28 kg. Destes, 57 \% são constituídos por entrenós maciços, $21 \%$ são ramos e $22 \%$, folhas (Tabela 2 ).

Uma nova touceira inicia seu estabelecimento com a produção de brotos muito finos (aproximadamente 1,0 $\mathrm{cm}$ de diâmetro), incapazes de se auto-sustentar. Se, na touceira adulta, os colmos se apresentam eretos na base e arqueados no ápice, nesta fase de implantação, o hábito é exclusivamente escandente. $\mathrm{O}$ novo colmo atinge o dossel da floresta apoiando-se na vegetação ao redor, ancorado pelos espinhos. A passagem para a fase juvenil se dá com a emissão de ramos clorofilados e folhas. A síntese, intensificada pela presença das folhas, garante maior autonomia para a nova touceira, que armazena substâncias de reserva e passa a produzir novos rizomas e colmos. Os rizomas iniciais são apenas uma fração dos rizomas das touceiras já estabelecidas (Figura 5).

Como proteção contra a herbivoria, rizomas e brotações são cobertos por folhas caulinares com intensa pubescência (CORREA, 2008). Nos rizomas, os nós muito próximos produzem sucessivas camadas destas folhas que preservam as reservas dos ataques de boa parte dos predadores, mas se mostraram ineficientes contra a lagarta de um Lepidoptera da família Noctuidae. Esta broca se instala nas gemas e pode provocar o abortamento das brotações, dificultando a multiplicação simpodial dos rizomas.

As folhas caulinares são triangulares, com lâminas eretas não pseudopecioladas, bainhas glabras na face abaxial e pilosas no dorso. Aurículas ausentes (aurículas presentes e fimbriadas na descrição de Londoño (2008)

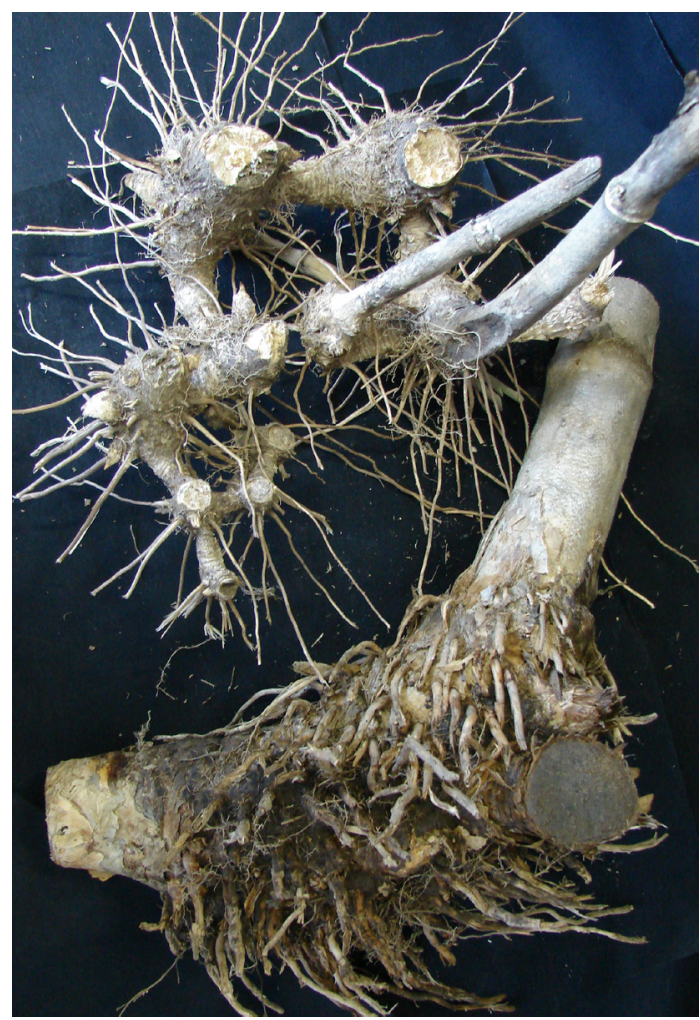

Figura 5. Comparativo entre rizomas de touceiras em implantação e estabelecidas.

e lígula interna não fimbriada. O comprimento total varia entre $23 \mathrm{~cm}$ e $60 \mathrm{~cm}$, e a largura na base, entre $16 \mathrm{~cm}$ e $26 \mathrm{~cm}$. Estas folhas recobrem os entrenós dos brotos tenros (com cerca de $80 \%$ de umidade) e caem, pressionadas pelo crescimento dos ramos, quando os colmos entram na fase juvenil. Os colmos, que logo após 
a queda das folhas caulinares apresentam pilosidade e têm superfície áspera, tornam-se lisos e opacos com o passar do tempo, em concordância com Londoño (2008). Também como defesa contra a predação, espinhos em forma de garra estão presentes na base dos ramos (Figura 4C). Os maiores estão nos ramos primários e dominantes, e os menores, nos demais.

Os nós apresentam uma característica faixa de tricomas brancos cuja largura varia proporcionalmente ao diâmetro do colmo, indo de $2,0 \mathrm{~cm}$ a $3,5 \mathrm{~cm}$, aproximadamente. Os colmos não são perfeitamente cilíndricos (cilíndricos para Londoño (2008)). Um sulco formado pela pressão da gema do ramo percorre longitudinalmente todo o entrenó.

O aspecto de "quilha de navio" (Figura 4E), característico dos colmos no início da fase juvenil, é resultado da busca pelo melhor aproveitamento da luz. A tentativa de garantir a máxima expansão da folhas (próxima etapa de desenvolvimento) provoca a projeção dos ramos para fora do plano descrito pelo arqueamento do ápice do colmo (quase horizontal devido à forte curvatura). Inseridos alternadamente, os ramos permanecem orientados verticalmente e descrevem entre si ângulos que variam de $80^{\circ}$ a $90^{\circ}$.

As folhas fotossintetizantes são lanceoladas (Figura 4D) e só são emitidas após os brotos superarem o dossel da floresta. São alternas, dísticas e pseudopecioladas. Possuem tamanhos diversos, são menores na base dos ramos e maiores nas pontas. O tamanho também varia segundo a idade da touceira: as folhas maiores estão nas plantas jovens e as menores nas mais velhas. Foram mais comuns as de $11 \mathrm{~cm}$ de comprimento e $0,7 \mathrm{~cm}$ de largura.

A deposição $G$. aff. paraguayana, formada predominantemente por folhas caulinares e dos ramos, atinge, nas barras, valores anuais de $7.5 \mathrm{Mg} / \mathrm{ha}, 95,90 \%$ da produção total deste ambiente. No período de acompanhamento, dezembro de 2006 a novembro de 2007, o maior aporte ocorreu nos meses de outubro e novembro, com pouco mais de $1.000 \mathrm{~kg} / \mathrm{ha}$ cada; e o menor, em fevereiro, com 329,64 $\mathrm{kg} / \mathrm{ha}$ (Figura 6).

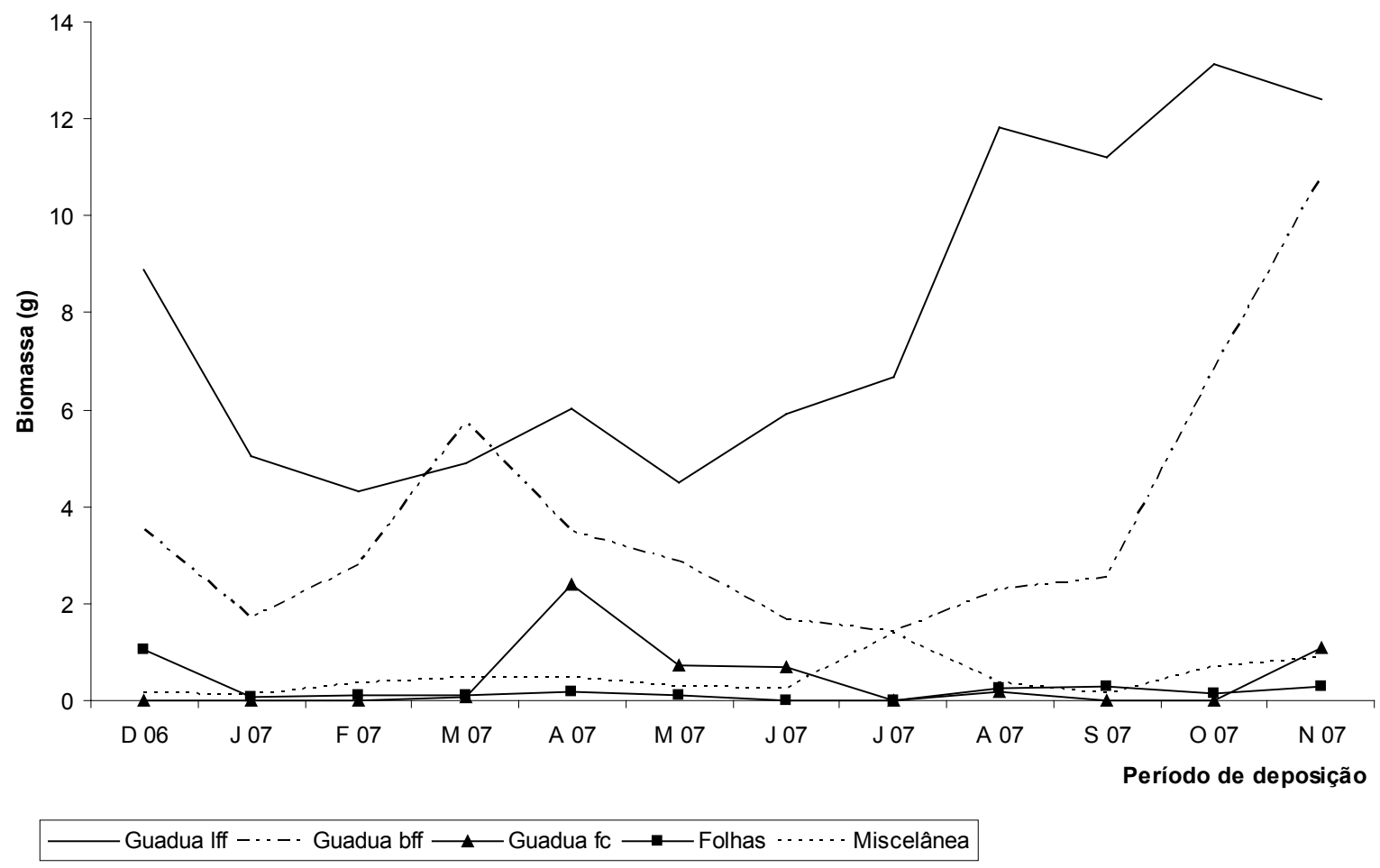

Figura 6. Deposição anual de serapilheira, em condição de barra, em FOMA sob influência de G. aff. paraguayana (lff: lâminas de folhas fotossintetizantes; bff: bainhas de folhas fotossintetizantes; fc: folhas caulinares). 
Nas interbarras, a deposição de G. aff. paraguayana (ocasionada pela projeção da porção apical dos colmos) atinge $3,46 \mathrm{Mg} / \mathrm{ha} / \mathrm{ano}$, ou 43,46 \% da deposição total.

Estes valores totais estão dentro do esperado para florestas tropicais - 5 a $15 \mathrm{Mg} / \mathrm{ha} /$ ano (BRAY \& GORHAM, 1964). Para a Floresta Ombrófila Mista (FOM), já foram registrados valores de $7,70 \mathrm{Mg} / \mathrm{ha} / \mathrm{ano}$ em São João do Triunfo, PR (FIGUEIREDO FILHO et al., 2003); 8,30 Mg/ha/ano, em Santa Catarina (FLOSS, et al., 1999). Para a FOMA nas margens do rio Barigüi, Araucária, PR, Sousa (2003) encontrou 9,44 Mg/ ha/ano. Houve mudanças no período de deposição. Na FOMA, onde predomina o branquilho, a maior produção de serapilheira ocorre no inverno. Onde $G$. aff. paraguayana está presente, a maior deposição se dá na primavera.

Em condição de barra, apenas a fração folha de $G$. aff. paraguayana responde por $93,83 \%$ da deposição.

Dados preliminares do estudo de ciclagem apontam para uma meia vida superior a seis meses para as lâminas e bainhas foliares. Para as lâminas, nos primeiros 180 dias de acompanhamento, houve decomposição de $36,5 \%$ do material em condição de barra, e de $45,3 \%$, em interbarra. Para as bainhas, a ciclagem é muito mais lenta. No mesmo período, em condição de barra, foram decompostos, em média, apenas $28,1 \%$ do material. Esta velocidade de ciclagem sugere acumulação de matéria orgânica.

A diferença nos ritmos de ciclagem das lâminas se deve às condições ambientais. As barras são regiões alçadas, livres de inundação frequente. Nas interbarras, a umidade está presente durante o ano todo.

\section{Conclusão}

A alteração da dinâmica de água no solo, provocada pelo remodelamento da planície de inundação - somatório das ações de mineração, desmatamento e agricultura-, é o componente que mais influencia a expansão de $G$. aff. paraguayana na área em estudo. $\mathrm{O}$ alçamento das barras cria o ambiente favorável à instalação do bambu. $\mathrm{O}$ sucesso no estabelecimento da espécie, no entanto, devese principalmente à sua estratégia de crescimento. No solo, as touceiras são formadas por apenas um indivíduo que se expande a partir de brotações extremamente vigorosas. Na parte aérea, os colmos superam o dossel num crescimento vertiginoso. Quando recebem radiação solar direta, formam uma espécie de trançado de ramos e folhas capaz de aumentar fortemente o sombreamento e suprimir a vegetação instalada, alterando os padrões de sucessão local.

O incremento médio na altura dos colmos supera largamente o das espécies arbóreas pioneiras de crescimento rápido.

O Refúgio da Vida Silvestre do Rio Tibagi deve cumprir sua tarefa de preservação em duas frentes. Além da área de cerca de 30 mil hectares em si - o parque permeia os municípios de Imbituva, Teixeira Soares, Ipiranga, Ponta Grossa e Palmeira -, espera-se que o espaço desempenhe o papel de corredor ecológico de vale, fazendo a conexão da Reserva Biológica de Imbituva e do Parque Nacional dos Campos Gerais com o Parque Estadual de Vila Velha e a APA da Escarpa Devoniana. A presença dominante de $G$. aff. paraguayana na FOMA local, no entanto, diminui a oferta de recursos alimentares para a fauna e altera a estrutura desta floresta, comprometendo seriamente o desempenho de suas funções ecológicas.

\section{Agradecimentos}

Ao Dr. Tarciso S. Filgueiras (Reserva Ecológica do IBGE), pelo complexo trabalho de identificação da espécie Guadua aff. paraguayana Döll. À Manoela Kowalczuck, Laboratório de Estudos de Lepidoptera Neotropical - UFPR, pela identificação da lagarta presente nas gemas dos rizomas.

\section{Referências}

BARDDAL, M. L.; RODERJAN, C. V.; GALVÃO, F.; CURCIO, G. R. Caracterização Florística e fitossociológica de um trecho sazonalmente inundável de floresta aluvial, em Araucária, PR. Ciência Florestal, UFSM, v. 14, n. 2, p. 37-50, 2004.

BRASIL. Ministério do Meio Ambiente. Proteção e recuperação da Floresta com Araucária: propostas de criação de novas unidades de conservação federais no Paraná e em Santa Catarina. Brasília, 2005, 16 p.

CARMO, M. R. B.; MORO, R. S.; NOGUEIRA, M. K. A vegetação florestal nos Campos Gerais - vegetação campestre. In: MELO, M. S.; MORO, R.S.; GUIMARÃES, G. B. Patrimônio dos Campos Gerais do Paraná. Ponta Grossa: UEPG, 2007, p. 93-98.

CORREA, P. G.; PIMENTEL, R. M. de M.; CORTEZ, J. S. de A.; XAVIER, H. S. Herbivoria e anatomia foliar em plantas tropicais brasileiras. Ciência e Cultura, São Paulo, v. 60, n. 3, 2008.

Disponível em: $<$ http://cienciaecultura.bvs.br/scielo.php?script=sci arttext\&pid=S0009-67252008000300017\&lng=en\&nrm=iso>. Acesso em: 04 Dec 2008. 
COSTENARO, G. A. R.; GALVÃO, F.; BOTOSSO, P. C. Avaliação do padrão dendrocronológico de Sebastiania Commersoniana (Baillon) L.B.Sm. \& R.J.Downs (Euphorbiaceae) em uma Floresta Ombrófila Mista Aluvial. In: CONGRESSO NACIONAL DE BOTÂNICA, 57.; ENCONTRO ESTADUAL DE BOTÂNICOS, 13.; ENCONTRO ESTADUAL DE HERBÁRIOS, 5., 2006, Gramado. Resumos do congresso. Porto Alegre: Sociedade Botânica do Brasil, 2006.

CRUZ, G. C. F. da. Alguns aspectos do clima dos Campos Gerais. In: MELO, M. S.; MORO, R.S.; GUIMARÃES, G. B. Patrimônio dos Campos Gerais do Paraná. Ponta Grossa: UEPG, 2007, p. 59-72.

CURCIO, G. R.; GALVÃO, F.; BONNET, A.; BARDDAL, M. L.; DEDECEK, R. A. A floresta fluvial em dois compartimentos do rio Iguaçu, Paraná, Brasil. Floresta, v. 37, p. 125-147, 2007.

DIAS, M. C.; VIEIRA, A. O. S.; NAKAJIMA, J. N.; PIMENTA, J. A.; LOBO, P. C. Composição florística e fitossociologia do componente arbóreo das florestas ciliares do rio Iapó, na bacia do rio Tibagi, Tibagi, PR. Revista Brasileira de Botânica, v. 21, n. 2, p. 183-195, 1998.

FIGUEIREDO FILHO, A.; MORAES, G. F.; SCHAAF, L. B.; FIGUEIREDO, D. J. de. Avaliação estacional da deposição de serapilheira em uma Floresta Ombrófila Mista localizada no sul do estado do Paraná. Ciência Florestal, v. 3, n. 1, p.11-18, 2003.

FILGUEIRAS, T. S. A floração dos bambus e seu impacto ecológico. Eugeniana, Nova Friburgo, v. 15, p. 1-8, 1988.

FILGUEIRAS, T.; GONÇALVES, A. P. S. A checklist of the basal grasses and bamboos in Brazil (Poaceae). Bamboo Science and Culture: The Journal of the American Bamboo Society v. 18, n. 1, p. 7-18, 2004. Disponível em: <www.americanbamboo.org/ ABSJournalArchive/index.html>. Acesso em: 22.02.2008.

FLOSS, P. A.; CALDATO, S. L.; BOHNER, J. A. M. Produção e decomposição de serapilheira na Floresta Ombrófila Mista da Reserva Florestal da EPAGRI/EMBRAPA de Caçador, SC. Revista Agropecuária Catarinense, v. 12, n.2, p.19 - 22, 1999.

FONT QUER, P. Diccionario de Botânica. Barcelona: Editorial Labor, $1^{\text {a }}$ edição. $1^{\mathrm{a}}$. edição, $7^{\mathrm{a}}$. reimpressão, 1979. 1244p.

IAPAR. Cartas climáticas do estado do Paraná. Londrina, 1994, 49p.

IPARDES. IPARDES: Perfil dos Municípios. Disponível em: $<$ http://www.ipardes.gov.br/perfil_municipal/EscolheMun.php $>$. Acesso em: 5 abril 2008

JUDZIEWICZ, E. J.; CLARK L. G.; LONDOÑO, X.; STERN, M. J. American bamboos. Washington, D.C. - USA: Smithsonian Institution Press, 1999. 392p.

LONDOÑ, X. Growth development of Guadua angustifolia: a case study in Colombia. Memorias. Bamboo and Its Uses. Procedings of na International Symposium os the Industrial Use of Bambueo, Beijing, China, 7-11 December 1992. International Tropical Organization and Chinese Academy of Foretry, Beijing, 1993.

LONDOÑO, X. Guadua Kunth. In: WANDERLEY, M. G. L.; SHEPHERD G. J.; GIULIETTI, A. M. Flora fanerogâmica do estado de São Paulo. São Paulo, SP: Instituto de Botânica: FAPESP: HUCITEC, 2001.
LONDOÑO, X. Especies de bambues de Argentina. Disponível em: <http://www.sagpya.mecon.gov.ar/new/0-0/programas/ prosap/informacion/bambu/especies bambues.pdf $>$. Acesso em: 15.02.2008

MAACK, R. Geografia física do estado do Paraná, 2. ed. Rio de Janeiro, RJ: José Olympio, 1981. 450 p.

MAGURRAN, A. E. Diversidad ecológica y su medición. Vedrá. Barcelona, 1989, 200 p.

MINEROPAR. Mapa geológico do estado do Paraná. Curitiba: DNPM-MINEROPAR. 1 mapa: color.; 1,97 X $97 \mathrm{~cm}$. Escala 1:650.000. 1989.

MISSOURI BOTANICAL GARDEN. Disponível em: <http:// www.tropicos.org/NameSynonyms.aspx? nameid $=40017788>$. Acesso em: 19.06.2008.

MUELLER-DOMBOIS, D.; ELLENBERG, H. Aims and methods of vegetation ecology. New York: John Wiley \& Sons, 1974. 547p.

OHRNBERGER, D. The bamboos of the world: annotated nomenclature and literature of the species and the higher and lower taxa. Elsevier, Amsterdam,1999. 585p.

OLIVEIRA FILHO, A. T. de; VILELA, E. A.; GALVILANES, M. L.; CARVALHO, D. A. Effect of flooding regime and understorey bamboos on the physiognomy and tree species composition of a tropical semideciduous forest in southeastern Brazil. Vegetatio, v. 113, p. 99-124, 1994.

PASDIORA, A. L. Florística e fitossociologia de um trecho de floresta ripiária em dois compartimentos ambientais do rio Iguaçu, Paraná, Brasil. 2003. 48 f. Dissertação (Mestrado em Ciências Agrárias) - Curso de Pós-Graduação em Engenharia Florestal, Setor de Ciências Agrárias, Universidade Federal do Paraná, Curitiba.

POZZOBON, M.; GALVÃO, F.; RODERJAN, C. V.; CURCIO, G. R.; DREZZA, T. R.; ANDRADE, B. O.; COSMO, N.; SANTOS, A. P. G. dos; STANGE JUNIOR, E.; VÖLTZ, R. R.; KAMINSKI, N. Influência de Guadua cf. paraguayana Döll sobre a estrutura e a regeneração de uma Floresta Ombrófila Mista Aluvial no alto rio Tibagi. 2009 (prelo).

RODERJAN, C. V.; GALVÃO, F.; KUNIYOSHI, Y. S.; HATSCHBACH, G. G. As unidades fitogeográficas do estado do Paraná. Ciência \& Ambiente, n. 24, p. 75-92, 2002.

SÁ, M. F. M. Os solos dos Campos Gerais - Solos. In: MELO, M. S.; MORO, R. S.; GUIMARÃES, G. B. Patrimônio dos Campos Gerais do Paraná. Ponta Grossa, PR: UEPG, 2007, p. 73-83.

SANTOS, H. G. dos; JACOMINE, P. K. T.; ANJOS, L. H. C. dos; OLIVEIRA, V. A. de; OLIVEIRA, J. B. de; COELHO, M. R.; LUMBRERAS, J. F.; CUNHA, T. J. F. da (Ed.). Sistema brasileiro de classificação de solos. 2. ed. Rio de Janeiro: Embrapa Solos, 2006. 306 p.

SANTOS, R. D.; LEMOS, R. C.; SANTOS, H. G.; KER, J. C.; ANJOS, L. H. C. Manual de descrição e coleta de solo no campo. 5. ed. Viçosa: SBCS, 2005. 92 p. 
SOUSA, S. G. A. de. Produção e decomposição de serapilheira de uma Floresta Ombrófila Mista Aluvial, rio Barigüi,

Araucária, PR. 2003. 127 f. Tese (Doutorado em Ciências

Florestais) - Setor de Ciências Agrárias, Universidade Federal do

Paraná, Curitiba.

Recebido em 18 de dezembro de 2008 e aprovado em 06 de agosto de 2009 